\title{
Research on the Teaching Value of Art Design Driven by the Project of Regional Visual Culture
}

\author{
Liu Ben, Dong Yumin \\ Xi'an University of Posts \& Telecommunincations \\ 834042002@qq.com
}

\begin{abstract}
The article comprehensively combs the teaching plan, the teaching content and the related teaching method of the digital art specialty. Through the "regional culture" project driven as the starting point, this article analyzes the basic characteristics and value of teaching, puts forward the corresponding teaching construction system and countermeasures, and highlights the diversification, innovation and continuous "high-level" practical teaching.
\end{abstract}

Keywords—regional culture; project driven; curriculum design

\section{INTRODUCTION}

Practical teaching of curriculum design is an important and necessary aspect to cultivate high-quality skilled talents. It is a necessary platform for students to understand the use of scientific methods and improve their ability. The new consciousness is to meet the teaching needs of the ordinary colleges and universities professional talents training needs. In accordance with the "Upgrade level, Enrich the connotation, Highlight the characteristics, speed up the success" development strategy, according to the relevant professional teaching plan and outline and the student's specialty purposeful selection related regionally teaching content, teaching organization form and teaching method, in the course of curriculum design, it optimizes the curriculum system, establishes the practice consciousness, puts forward the corresponding question, the interaction between teachers and students, and finally discusses the solution, which is related to the regional teaching content, teaching organization form and teaching method. On the curriculum design practical teaching for effective reform and strengthening, highlighting the "regional culture" concept of practice, it is an important means to improve the quality of applied teaching in the curriculum design of professional design of visual arts [1].

Colleges and universities, as an important place to teach science and technology culture, and as a teaching college, are responsible for cultivating the mission of talent who have the ability to innovate and practice. From the interests of local economic development, from the "static" passive teaching to "dynamic" active practice, Colleges and universities should change the past closed, a single static to keep the classroom, change the teacher's simple knowledge teaching, and strengthen regional, local culture, economic development services, interactive practice. Colleges and universities should enhance their ability in the affirmative problem solving and tap

2016 Xi'an University of Posts and Telecommunications Young Teachers Research Fund Project: "Shaanxi cultural industry development value research" stage results 2016001; their own potential in the positive thinking of innovation.

As the core competitiveness of local colleges and universities, it is necessary to participate in the actual project of "regional" visual culture construction to fully mobilize the students' meticulous observation, analysis and hands-on ability to solve the problem so that students can use their own knowledge to understand their interdisciplinary and multidimensional cross-cutting and complexities of the relevant disciplines to accomplish the actual design tasks [2] in order to enhance their own creative level. Excellent and best design can provide a "modern" construction text for regional cultural protection and research, and it also can provide relevant theoretical basis for investment, decision-making and conservation assessment of cultural administration. Through the real project of the "regional cultural project-driven", it adapts to the needs of the market for talent.

\section{CONTEMPORARY TEACHING VALUE OF "REGIONAL CULTURE" OF PROJECT - DRIVEN MODEL}

Chinese art design disciplines have a relatively special law, fully applied science and engineering or complete humanities practice evaluation criteria will certainly "irrelevant to the subject." Most of the status quo is a heavy face, light liar, academic anomie, evaluation standard imbalance, evaluation results distortion, the focus is not playing a good foundation, the key is to seize the cultivation of the root. Now the practice of curriculum design disciplines and indicators evaluation system has brought many difficulties to the healthy development of art design disciplines. As the current status quo has not yet set a set of standards and evaluation system that can reflect the characteristics of the art design discipline. Most of the evaluation practice applies a mixed measure to control it. As the third-tier cities in the local institutions, in the recruitment, teacher input, teaching conditions and the level of students and the quality of the national key 985,211 institutions have a greater gap. In the relatively narrow and limited school conditions, to find, seek and break through the bottleneck of personnel training, improve the quality of training is the primary task of the current educators. Teaching work as a common and frequent work of local colleges and universities, we must face the social needs and serve the local economic construction and development [3]. "Regional culture" project-driven used to serve the local economy, which is innovative, pragmatic and forward-looking practical curriculum system, which not only highlights the local 
university's characteristics, but also related to the school as a student practice to the group and the individual "survival" extension. This project will optimize the curriculum system, increase the intensity of practice, match the corresponding teachers, pay attention to innovative personnel training and construction, and encourage students to get out of the school to participate in local economic issues of joint and collaboration. "Regional culture" project to drive a relatively wide range of coverage, so in the second semester, sophomore year, junior year, the first semester, six semesters in stages, sub-categories of contact and research. According to the different qualities and characteristics of the students can be a thematic discussion and the difficulty is relatively easy, the scope of the wide range of multi-contact. "Read all the books, and go all the way." Practicing the truth, creativity is the soul. In the "visual communication" professional work process, both are indispensable. "Visual Communication" is a comprehensive discipline of pure art (Chinese painting, engraving, sculpture, oil painting, etc.) and designed to cross, integrate and integrate as a kind of marginal subject with both flexibility and painting, design and creativity., The most basic elements of visual design, can well reflect the formal characteristics of graphic design. Therefore, to talk about its regional, local cultural construction and development services have a very objective and practical significance.

Through the "regional" visual culture project, so that students hold professional ability to examine, observe and participate in it from the perceptual level of consciousness, "regional" visual culture construction of the actual project site visits, to obtain the more primitive First - hand text. Paying attention to daily life, systematic research, systematic sorting, in previous research results and field investigation to visit the text on the basis of comparative analysis to draw a more regular conclusions. Once again, the use of human culture, art, ethnology, philosophy, law, management, interdisciplinary, pedagogy, economics, archeology, history, logic, sociology, statistics, psychology, journalism Communication, linguistics, political science and religion and other disciplines of thinking methods and concepts of "regional" cultural construction of the actual project to consider the cultural form. In the field study, the paper focuses on the field work, and makes qualitative analysis on the basis of scientific and verifiability. Let students learn to use the "regional" visual language for creative expression and skill exchange. Can be more accurately aware of the "regional" visual cultural project-driven status quo; Mastering, understanding and clarifying "regional" project-driven culture points; Rapid, more skillful use of different styles of "regional" materialized modelling and color language for creative design performance. Tapped the hidden qualities of a student, pay attention to engine high-order thinking ability, Focus on high-level thinking ability to the engine, information collection and sorting, collective cooperation and division of labor refinement, the good faith quality compatible with critical check introspection, thinking, active collaboration, bears hardships and stands hard work, steadfast, honest and true to explore implicit knowledge, ability and so on self-discipline and enterprising development.

\section{THE DEFINITION AND CONSTRUCTION OF CONTEMPORARY TEACHING SYSTEM OF "REGIONAL VISUAL CULTURE" PROJECT}

The modern and standardized production revolution and the rise of modern cities is treated as the basic measure of the modern era, which greatly changes the agricultural society of human life, and the superstructure and ideology of correspondingly changes. "Regional" cultural construction of the actual project is driven by the real positive energy stimulation, which will guide the students to develop healthily. Visual communication professional curriculum design is a kind of inevitable practice teaching exists, which is complicated with the hardships, helpless and abrupt, but the teaching practice must hold the value of the standard. Thinking and emotional changes should clarify the "invisible" waste oil to identify "Big head "of the milk powder. It will not be made or extended by the enthusiasm of the society; leaving the "regional" culture of teaching and education practice is making his mark, the so-called "regional" culture construction project drive is a relatively comprehensive understanding and grasping, review of geographical culture [4]. Benign stimulation, active plain of inheritance, the development of analysis and criticism are the cause of these different materials of different heterogeneous exotic culture from time to time (generally refers to different region), which will invade into the real life, be applied to materialization and visual media, and bring us many benefits. It is a rich store of "visual" value source. On the other hand, if we do not finish it in time, we will face the crisis of decline and extinction. This is not blind to sing for the "regional" cultural points, but it is a duty, a powerful mission and responsibility. The paper analyzes the influence of the traditional "regional" culture on the vertical displacement, the horizontal and horizontal movement, and the influence of the vertical, horizontal or reverse construction. How much energy can the inheritance practice bring to the present culture and how much sharing factors can be put into and can influence how many aspects and how many people.

On the one hand, we should go to check, classify and sort out the outstanding traditional visual materialized language, and push it out. On the one hand we should absorb, learn different areas of excellent traditional visual materialization language, which is one of the most basic cognitive problems of "regional" Cultural construction of the actual project to drive the development. We cannot be blind and think that only their own is the top, the most advanced and the best. We even unreasonably criticize active close examining of "regional culture", instead, we should do "regional culture" research, the monarch must feel on the way to the source culture time and hold their own value judgment standard.

This is the basic condition of education, the current art design major. Non-ideal candidates' participation and the bad quality of the art design practitioners make the professional education teaching and practice of the clutter abnormal and have no standards. Fire range of extreme good and squalid a variety of factors, attitudes and skills are mixed together. The real art design major education teaching should be the most agile technology and art in the face of social reality and progress. Its connotation is in the field of practical arts and arts and it is the excavation of practical craft art and extension of 
extension. We should rely on the advantage of modern science and technology platform and multidisciplinary collaborative innovation to satisfy the masses of material and spiritual growing art design requirements, to provide suitable modern living environment and the mode of production for people. This requires a solid cultural base, industry knowledge and skilled skills.

Through the "regional" project driven visual culture is to further highlight the "regional" cultural characteristics, the concept has been driven from the original one yuan to two yuan in the development of thinking of thinking, it should see two attributes .

A. Public welfare;

\section{B. Industry;}

Mainly reflected in the following the following aspects:

- $\quad$ From the practice object, to "regional" cultural works exhibition, art exchange, creative achievements and talents incubation and entrepreneurship as the research platform. It is targeted.

- $\quad$ From the point of view of research content, the paper focuses on the path and mode of education inheritance and protection.

- From the perspective of research methods, issues related to inheritance and protection system of regional culture found for incision, rather than to further demonstrate sophisticated hypothesis and the hypothesis of the path stages sampling and further consolidation, we should take thinking methods and related empirical research by comparative research as the main research countermeasures. Method is proper.

- From the research goal, the inheritance and protection of the "regional" cultural construction under the vision of practice to construct standard which is consistent with the characteristics of the times and reflect the market-related development requirements, is helpful to study the existence of Manchu intangible cultural heritage, the methods of review and the existence of objectives and other aspects of the reform measures, but also is helpful for the local government and education administrative departments of decision-making and evaluation criteria to lay the relevant theoretical and practical basis. "Regional" cultural construction of practical projects to drive deep and "regional" cultural heritage of the historical development of the value of the origin of the Manchu totem and faith; wide and "regional" cultural heritage and protection of cultural applicability, culture soft power and its contemporary market application analysis so as to re-examine the ancient "regional" culture and art, measure its development and future, and its folk art modeling, color system is reasonable to apply to teaching practice to make big teaching effect.

"The biggest feature of regional" visual culture is written form, freehand, writing to God, writing the heart, exaggerated peculiar imagination, profound connotation and is favorable evidence research, mining history and culture, aesthetics and other aspects of the history. It is one of the traditional arts of the Chinese nation. It is the cultural form of both appreciation and utility. It bears heavy traditional culture and national spirit. It maintains a complete and rich cultural evolution and historical traces of the group of ancestors, which forms a unique style of special beauty.

As a public cultural product, the regional visual culture should be considered in a multi-dimensional space. It has complex characteristics, not only has the public welfare and industrial components in the investigation and assessment on the basis of the multivariate and universal way of interpretation and application of the "regional" cultural heritage [5]. The interpretation on how it fits with the modern society and the future social development fit is an unavoidable fact. It is the "regional" cultural heritage "education" and "modern transformation" and protection research. Nowadays, we should seize the good opportunity to carry out a comprehensive protection of regional culture, based on the full integration of the existing research results, further physical carrier and related information field search, collation and research of "regional culture", while inheriting people to spare no effort to cultivate the systematic organization, relevant research institutions on the basis of formation of creative design, production, sales of circulation, such as education and training industry chain, make its history, culture, art, and promote the market value.

\section{CONCLUSION}

When "Regional" visual culture project-driven teaching began to implement, some teachers and students cannot accept, suspect, wait and see, and make irresponsible remarks. Violent criticism and other words and deeds is inevitable. Because it has changed the years of study and living habits, and it is a new model practice. Walking close to the wet earth is a "surgery industry has a test", "surgery industry to be tested," the basic repair of the students. Being close to the times, close to the professional and close to the mainstream consciousness, along the talent "to Degree "and responsibility, the purpose is to improve the students' participation, enrich the knowledge cultivation and sharpen the top quality and quality, enhancing the ideological dimension, in the conditions of adaptation and satisfaction to meet the situation more convenient growth talent needs. Because the students' "practice" is the social "objective needs" exchange. The implementation of training mainly includes the following two aspects: clearing the main purpose and analyzing obstacles encountered. In the organization and the implementation of "project-driven" under the curriculum design, the teacher bases on the project's ultimate goal, method and schedule so that students can rely on the task, sort out the problem, in the process of solving the problem and learn and master the knowledge and skills that can get verified, upgraded. Through the summary of the proposed problem to introduce the expertise involved, highlighting the main points and explaining the difficulties can mobilize students to analyze and discuss, let them participate in the project practice, innovation to explore the best solution to the problem and a detailed solution to complete the task of 
the various paths. According to the "regional" cultural project to drive people to complete their own tasks, it will no longer learn to taste as chewing with the boring burden, but rely on the project's initiative to explore their own doubts or the knowledge they completely do not understand. It will change the past, a single indoctrination "rice to mouth".

"Regional" visual culture project is the driving force of high school personnel training and its important means and links. Chinese and foreign institutions are the same. It is the form of pluralistic package. Its application to the knowledge literature, the measurement of the theoretical level, the use of foreign language and computer, the evaluation of innovation quality, the overall understanding of objective reality, the understanding of new information and new materials and quasi-designer of the professional knowledge reserves are a very good, very high promotion. Through the "project-driven", we can improve the quasi-designer and future designer's understanding, and mine its rich "artistic potential" in practice.

\section{REFERENCES}

[1] National Medium and Long Term Education Reform and Development Plan (2010-2020): People's Publishing House, 2010, 16 pages;

[2] Research on the Development Strategy of Chinese Art Design Education: Research Group of Chinese Art Design Education Development Strategy, Tsinghua University, Tsinghua University Press, 2010, 22 pages, 56 pages;

[3] Yuxian Chen ;Practice in German Universities of Applied Technologies and Its Inspiration for China's Application-Oriented Colleges,Journal of National Academy of Education Administration [D], 2015, (5) ;

[4] Ming-hui SHAO ; Construction and Exploration of Multi Discipline Integrated Practical Teaching Mode, Research and Exploration in Laboratory [D] , 2016, 35(8). 